fatigue of industrial significance. The Industrial Health Research Board recently obtained evidence of the effect of a noisy environment on industrial output. Thus, weavers gave a significantly higher output when provided with ear defenders; and a similar result was obtained with typists using noiseless typewriters. In addition, there are many examples of noise, depending on time and place, which offend the great mass of people. Scientific investigation can here form the basis of legal control, if desired by an enlightened public.

The scientific measurement of the minute acoustic power which appears as a loud noise is greatly assisted by microphone and amplifier technique. The loudness scale is taken as a logarithmic scale, with the decibel as the unit, with a zero-level of the order of 0.3 milli-dyne per sq. cm., which will probably be internationally fixed in the near future. For a specified noise to be measured, it is compared with an adjustable standard tone, a pure 1,000 cycle-per-second note. In Germany, the unit of loudness of the standard tone is called the phon; it is suggested that this unit be generally adopted, restricting the decibel unit to purely intensity measurements or levels.

The two main methods of comparing a specified noise with the controllable standard noise are (l) the objective measurement, with microphone, amplifier, and indicator, and (2) the subjective measurement of loudness by audiometers, using matching or masking of the noise with the standard tone, employing the ear as the indicator.

The objective methods require calibration against absolute standards, such as the Rayleigh disc. Correcting networks are required for the non-uniform response of the system with frequency, and weighting networks are required for the simulation of the differential frequency sensitivity of the ear. The objective method is well suited for the rapid estimation of noises of similar type. Objective meters also permit a ready demonstration of the component frequencies in a sound, thus permitting the source of specified frequencies to be traced and controlled.

Subjective methods, by masking or matching, are likely to be standardised between the leading countries, the balancing to be done with both ears, with the observer facing the source of sound. Such methods require trained observers for uniform results. It has been noticed that the adjustment with audiometers should be from the loud side, rather than the reverse, or both. Audiometers are not well adapted for shortperiod or fluctuating noises. A simple type of audiometer is a tuning fork, struck in a specified manner, and having a known rate of decay.

Surveys have recently been made by the National Physical Laboratory. Ordinary conversation registers about 50 decibels, a tube train about 80 , while the loudest sounds, such as from riveting, pneumatic road-drills, steamship sirens, printing presses and aeroplane engines, are represented by figures up to 110 decibels. Traffic noises arise from the increase in the number of vehicles and narrow streets, though there is some evidence that the average vehicle is quieter than a few years ago. The modern bus and trolley-bus are great improvements over the older bus and tram. The introduction of pneumatic tyres on heavy vehicles is a commendable step. Noise, then, no longer comes from the road surface, but mainly from the transmission and exhaust, which are controllable. Noisy hooters and the modern sports car are major factors in the generation of traffic noise, many flouting the law (Traffic Act, 1930) on the score of ineffective engine silencing. Motor cycles are major offenders; developments have shown that real silencers can be fitted as a first step in reducing the total noise, the design depending on acoustic filtration of the generated frequencies.

National Physical Laboratory trials with motor horns support the view that stridency is related to the presence of loud high-frequency components. Hooting is to be regulated. Abroad, many cities hav' adopted nocturnal freedom from hooting.

In the control of noise-levels, industry as a whole seems to be becoming active, since the welfare of the worker is involved. Much has been done in aircraft silencing, particularly in the cabins, by the improved disposition of the engines and the use of isolating wall construction. In the field of quiet housing, new equipment has been installed at the National Physical Laboratory for the systematic investigation of building materials.

\title{
The Forests of Kenya
}

\section{$\mathrm{T}$} HE annual report of the Forest Department of the Protectorate and Colony of Kenya up to December 31, 1932 (Govt. Printer, Nairobi, 1933) reflects the present position of most of the forest departments of the Protectorates and Colonies under the Colonial Office. The report opens with the sentence, "The world-wide economic depression continued to affect the Colony and to an even more serious extent than in the previous year, with the result that revenue continued to decrease and further economies became essential". It is of course unavoid. able that the heads of the forest departments should concern themselves primarily, even at the expense of professional practice, with the revenue receipts from the forests under their charge. For it is apparent that certain of the governors and their advisers are only able to envisage the forests and a forest policy from the point of view of the monetary return that can be extracted from the forest estate.

As is well known, in countries in Europe where a forest policy and forest administration have for long been working hand in hand, those responsible for the professional management of the forests assume that revenue shall exceed expenditure, and that the department shall be one of the revenue resources of the State. In the case of ill-developed areas of forest with considerable potential possibilities, the effort to obtain revenue at the expense of real efficiency is, in the long run, inevitably disastrous.

Kenya is not the only Colony which is now suffering from a similar policy. In the immediate post-War years (if we omit the pre-War period and possibility of development in some Colonies) a broad forest policy coupled with a bold expenditure devoted to enumerations of the growing stock of unexplored forest areas and opening out the most accessible ones, would have assuredly placed the various forest departments on a sounder basis, and have enabled them to withstand better the depression of the last few years. The vacillating policy adopted left the departments in the most cases undermanned and weak, with the result that they have suffered probably to a greater 
degree from the severe cuts in establishment and so forth which have been their lot during the past few years-an action which will delay the development of the valuable forest estates under their control, and the consequent revenue to be derived from these estates, by a decade.

This being the position of affairs, it is not surprising to find the Conservator of Forests of Kenya devoting the opening paragraphs of his report to the financial position of his Department.

The Kenya forests are probably, in the interests of the economic development of the Colony, of so great a value that the statement that expenditure was reduced to $£ 31,691$ as compared with $£ 36.237$ in the previous year and that the cash revenue was $£ 26,156$, showing a deficit of $£ 5,353$, appears of trivial importance; when the far graver issues dependent upon the maintenance and correct management of this valuable property are taken into consideration.

It seems clear from the report that the drop in timber sales is only a temporary matter and that the normal requirements of the Colony will in due course witness a rise.

Owing to shortage of staff and the orders to economise, the area replanted, although said to be equal to the area felled during the year, showed a decrease on the preceding year's acreage, being 3,892 acres as against 4,756 acres in 1931 and 4,429 acres in 1930 .

In spite of troubles brought about by irregular rainfall and locusts - the Colony has experienced bad invasions of this pest for several years past-it was estimated at the end of the year that 73 per cent of the area planted was completely established, 26 per cent was fair and 1 per cent only had failed-a record sufficient to satisfy the most ardent planter. Improved organisation and increased economy of working is shown in this planting work, the average cost falling from $8 \cdot 86 s$. to $7 \cdot 13 s$.; this figure includes the cost of work in 1931 in preparation for the 1932 planting but does not include supervision or nursery costs.

The Conservator appears to be concerned with the timber being cut in the small forests still existing on private land which "was often sold for anything it would fetch and had a most demoralising effect on the timber market". In the early days in India, when Sir Dietrich Brandis was introducing a forest management and selecting reserves, he regarded the felling of timber on the private estate as assisting in providing for market requirements. His view was that these operations were an assistance to the State since it allowed the forest officer time to consolidate his selected areas of forest and to introduce an effective system of management. But at the time, it was recognised that some forest divisions or conservators' charges could not be expected to yield a revenue until effective organisation had been introduced, and the cheap material on private lands had been exploited and had disappeared.

\section{International Congress for Applied Mechanics}

\section{Cambridge Meeting}

$\mathrm{T}$ HE fourth International Congress for Applied Mechanics was held in Cambridge under the presidency of Prof. C. E. Inglis on July 3-9. About 320 members attended, including representatives of twenty-three countries. More than 140 papers were read, in four sections dealing respectively with general mechanies, hydrodynamics, strength and properties of materials, water waves.

Besides these sectional papers, seven general lectures were delivered by invitation describing recent progress in some of the main fields of science covered by the Congress. The general lecturers were Prof. V. Bush on analysing machines, Prof. A. Caquot on the elastic limit in isotropic materials (in French), Prof. J. P. den Hartog on vibrations in engineering, Prof. Th. v. Karman on turbulence, Prof. E. Schmidt on heat transference (in German), Prof. G. I. Taylor on the strength of erystals, Prof. H. Wagner on bodies gliding on the surface of water (in German). This list gives some idea, though by no means a complete one, of the range of subjects covered by the Congress.

The subject which perhaps attracted the greatest amount of attention was turbulence in fluids. There were present at the Congress most of the principal workers in the subject in the world. Prof. L. Prandtl spoke on the application of the laws of turbulent flow to the general circulation of the atmosphere. Dr. Schlichting gave an account of experiments at Gottingen on flow through a tunnel which was heated from above so that turbulence was reduced owing to a stable gradient of density. Dr. H. L. Dryden and Mr. Waltendorf spoke of measurements of turbulence made with hot wires at the Bureau of Standards, Washington, and at Pasadena. From the National Physical Laboratory, Teddington, Mr. A. Fage described his measurements of turbulence by an ultramicroscope; Mr. H. C. H. Townend, measurements by observing the motion of spots of air heated by a succession of sparks; and Mr. E. F. Relf, the effects of turbulence on force measurements made in the new compressed air wind tunnel. From Cambridge, Prof. B.M. Jones described measurements made on an aeroplane in flight of the region behind the wing where the flow is turbulent. From the laboratories of Prof. H. Benard and Prof. D. Riabonshinsky in Paris, work on vortices in fluids was described.

Owing to the large number of the scientific papers presented, it was impossible to publish them in full. In most cases they have been, or will be, published elsewhere, but abstracts were printed for the use of members at the meetings, and these will be reprinted in a volume which will also contain the seven general lectures, printed in full, and a short general account of the Congress. This volume, costing $£ 1$, will be ready in a few months' time and will be obtainable from the Secretary, Fourth International Congress for Applied Mechanies, Engineering Laboratory, Cambridge.

The Congress was entertained at evening receptions by the Mayor of Cambridge and by St. John's College, at a conversazione and exhibition of instruments and demonstrations by the Engineering Laboratory, at a garden party by Christ's College, at dinner by the Organising Committee and Trinity College and afterwards by Sir J. J. and Lady Thomson, and by the Provost of King's at a concert.

International Congresses for Applied Mechanics are held every four years. The first three were at Delft, Zurich and Stockholm, respectively. The fourth was at Cambridge, England, and the fifth will be held in 1938 at Cambridge, Massachusetts, under the auspices of Harvard University and the Massachusetts Institute of Technology. 